\title{
BMJ Open Factors associated with polypharmacy and excessive polypharmacy in older people with intellectual disability differ from the general population: a cross-sectional observational nationwide study
}

\author{
Máire O’Dwyer, ${ }^{1,2}$ Jure Peklar, ${ }^{3}$ Philip McCallion, ${ }^{4}$ Mary McCarron, ${ }^{5}$ \\ Martin C Henman ${ }^{1}$
}

To cite: O'Dwyer M, Peklar J, McCallion $\mathrm{P}$, et al. Factors associated with polypharmacy and excessive polypharmacy in older people with intellectual disability differ from the general population: a cross-sectional observational nationwide study. BMJ Open 2016;6: e010505. doi:10.1136/ bmjopen-2015-010505

- Prepublication history and additional material is available. To view please visit the journal (http://dx.doi.org/ 10.1136/bmjopen-2015010505).

Received 10 November 2015 Revised 3 February 2016 Accepted 7 March 2016

CrossMark

For numbered affiliations see end of article.

Correspondence to Dr Máire 0'Dwyer; modwyer6@tcd.ie

\section{ABSTRACT}

Objectives: (1) To evaluate the prevalence of polypharmacy (5-9 medicines) and excessive polypharmacy (10+ medicines) and (2) to determine associated demographic and clinical characteristics in an ageing population with intellectual disabilities (IDs).

Design: Observational cross-sectional study.

Setting: Wave One (2009/2010) of the Intellectual Disability Supplement to the Irish Longitudinal Study on Ageing (IDS-TILDA).

Participants: A nationally representative sample of 753 persons with ID, aged between 41 and 90 years. Participants/proxy reported medicines (prescription and over the counter) taken on a regular basis; medication data was available for 736 participants (98\%).

Main outcome measures/interventions: Participants were divided into those with no polypharmacy (0-4 medicines), polypharmacy (5-9 medicines) and excessive polypharmacy (10+ medicines). Medication use patterns were analysed according to demographic variables and reported chronic conditions. A multinomial logistic regression model identified factors associated with polypharmacy (5-9 medicines) and excessive polypharmacy ( $\geq 10$ medicines).

Results: Overall, $90 \%$ of participants reported use of medicines. Polypharmacy was observed in $31.5 \%$ of participants and excessive polypharmacy in $20.1 \%$. Living in a residential institution, and reporting a mental health or neurological condition were strongly associated with polypharmacy and excessive polypharmacy after adjusting for confounders, but age or gender had no significant effect.

Conclusions: Polypharmacy was commonplace for older adults with ID and may be partly explained by the high prevalence of multimorbidity reported. Review of appropriateness of medication use is essential, as polypharmacy places ageing people with ID at risk of adverse effects.

\section{Strengths and limitations of this study}

- This is a comprehensive examination of the patterns and factors associated with polypharmacy and excessive polypharmacy in a representative older population with intellectual disability (ID). The use of the two thresholds for multiple medicine use (ie, polypharmacy and excessive polypharmacy) have not been utilised before in ID population, and the threshold of 10 or more indicates greater risk.

- The sample is representative of the national ID population in Ireland from which it was drawn meaning that these findings have the potential to be generalised to other populations with ID, and was sufficiently large that our multivariate analysis had sufficient power. The great majority of respondents recorded medication data (98\%), and detailed collection of medication use allowed for accurate cross-sectional capture of medicines a participant was taking, including over-the-counter medicines.

- Participants and/or proxy respondents completed a detailed assessment of health characteristics, permitting examination of potential confounders in the regression model. While we cannot rule out other residual confounding, in our multivariate analysis we took into account demographic and other clinical potential confounders.

\section{INTRODUCTION}

People with intellectual disability (ID) have up to 2.5 times the number of health problems reported for the general population ${ }^{1-4}$ and are more likely to be exposed to health inequalities and social determinants of poorer health such as poverty, unemployment and discrimination. ${ }^{5}$ There is a higher incidence of comorbidities such as psychiatric conditions, epilepsy, dental disease, 


\section{Strengths and limitations of this study}

- Chronic conditions and medication use reported was based on participant or proxy self-report. However, the information gathered in the preinterview questionnaire (PIQ) was crosschecked at the time of interview and participants were given sufficient time before the PIQ was returned to gather the information. Such verification of information at the time of interview provides greater reliability than self-report recall methods alone.

- We do not know the extent to which answers in the face-to-face interview may have been influenced by the combination of responses styles. Those with severe or profound ID were more likely to have a proxy-only interview or a mixed answer style which enabled non-verbal participants, or those with severe ID to partake.

dementia and osteoporosis. ${ }^{36}$ Nevertheless, people with ID are experiencing increased longevity and by 2020 the number of ageing people with IDsis projected to double. $^{78}$

Detection and diagnosis of illness are more complex for this population ${ }^{3} 6^{9}$ and may contribute to the overuse and underuse of medicines. Moreover, recent studies indicate differences in the severity and combinations of comorbid conditions in people with ID as they age. ${ }^{10} 11$ There is a high incidence in people with IDs of dual diagnosis: the co-occurrence of IDs and mental illness ${ }^{12}$ with one study reporting $41 \%$ of adults with IDs with mental illness. ${ }^{13}$ Aggression, over activity, selfinjurious behaviours or 'challenging behaviours' have been reported at rates of up to $60 \%$ in studies of people with IDs. ${ }^{14}{ }^{15}$ Mental health and neurological concerns increases the likelihood of polypharmacy. ${ }^{16}$ Use of multiple drugs and long-term use of some types of drugs in this population may cause preventable harm. ${ }^{12}{ }^{17}$ This risk of harm and complexity of prescribing is compounded by age-related adversity risk and the presence of organic dysfunction associated with the ID which may lead to idiosyncratic responses, and increased sensitivity to drugs. ${ }^{18-20}$ In Ireland and in other developed countries, increasing emphasis on deinstitutionalisation and community integration also means greater utilisation of primary care services where there may not be specialist knowledge of the unique issues for people with IDs as they age.

Limitation of polypharmacy and of psychotropic use has been encouraged as one of the core elements of 'good physical health' in older people with IDs. ${ }^{3} 6$ Polypharmacy has been identified as a key indicator of quality of healthcare for people with IDs, as polypharmacy may cause harm and require clinical attention in this population. ${ }^{17}$ However, studies relating to the patterns, prevalence and predictors of polypharmacy exposure in older adults with IDs are scarce. ${ }^{6}{ }^{21}$ Given the potential for increased adverse consequences for people with IDs from multiple drug use and from frequent reliance on general population data and recommendations, it is important that there be studies of the patterns of drug use particular to people with ID.

To address this need, the primary objectives of this study were;

1. To determine the prevalence and patterns of polypharmacy and excessive polypharmacy, and the relationship of medicine use to patterns of medical conditions in a representative sample of ageing people with ID,

2. To identify demographic and clinical factors associated with polypharmacy and excessive polypharmacy in an ageing population with ID.

\section{METHODS}

\section{Study design}

Medication data for this study was drawn from the 2009/ 2010 Wave 1 of the Intellectual Disability Supplement to the Irish Longitudinal Study on Ageing (IDS-TILDA), which contains 753 persons with ID, aged between 41 and 90 years $^{22}$ (figure 1). The IDS-TILDA study has been described in detail elsewhere ${ }^{1022}$ and further details of the representativeness of the sample are available in online supplementary tables S1 and S2. In summary, IDS-TILDA is a nationally representative, longitudinal study of older adults with IDs designed to explore aging profile, physical and behavioural health (including medication use), health service needs, psychological health, social networks, living situations, community participation and employment. A preinterview questionnaire (PIQ) was sent to each participant at least 1 week in advance of a face-to-face interview. Additional data were gathered in a subsequent face-to-face interview and PIQ reports were also confirmed in this interview. A number of different interviewing styles were offered to the participants given their differing levels of ID and abilities to communicate; a respondent-only interview conducted directly with the individual ( $\mathrm{n}=147 ; 19.5 \%)$, a proxy interview completed with a family member or carer most familiar with the person $(n=265 ; 35.2 \%)$ or an interview with the person was supported by a familiar family member or carer $(\mathrm{n}=314 ; 41.7 \%)$. A small number of participants required a combination of these approaches $(n=27,3.6 \%)$. We have followed the Strengthening the Reporting of Observational Studies in Epidemiology (STROBE) standardised reporting guidelines for cross-sectional studies. ${ }^{23}$

\section{Medication exposure measures}

\section{Participants/proxy were asked in the preinterview} questionnaire

'Can you tell me what medications (including prescribed or over the counter (OTC)) and supplements you take on a regular basis (like every day or every week)? ${ }^{22}$

Medicines were recorded by brand/generic name, including prescription and non-prescription, OTC, herbal and alternative medicines and food supplements, and where available, the dose and frequency. 
Figure 1 Flow chart for study.

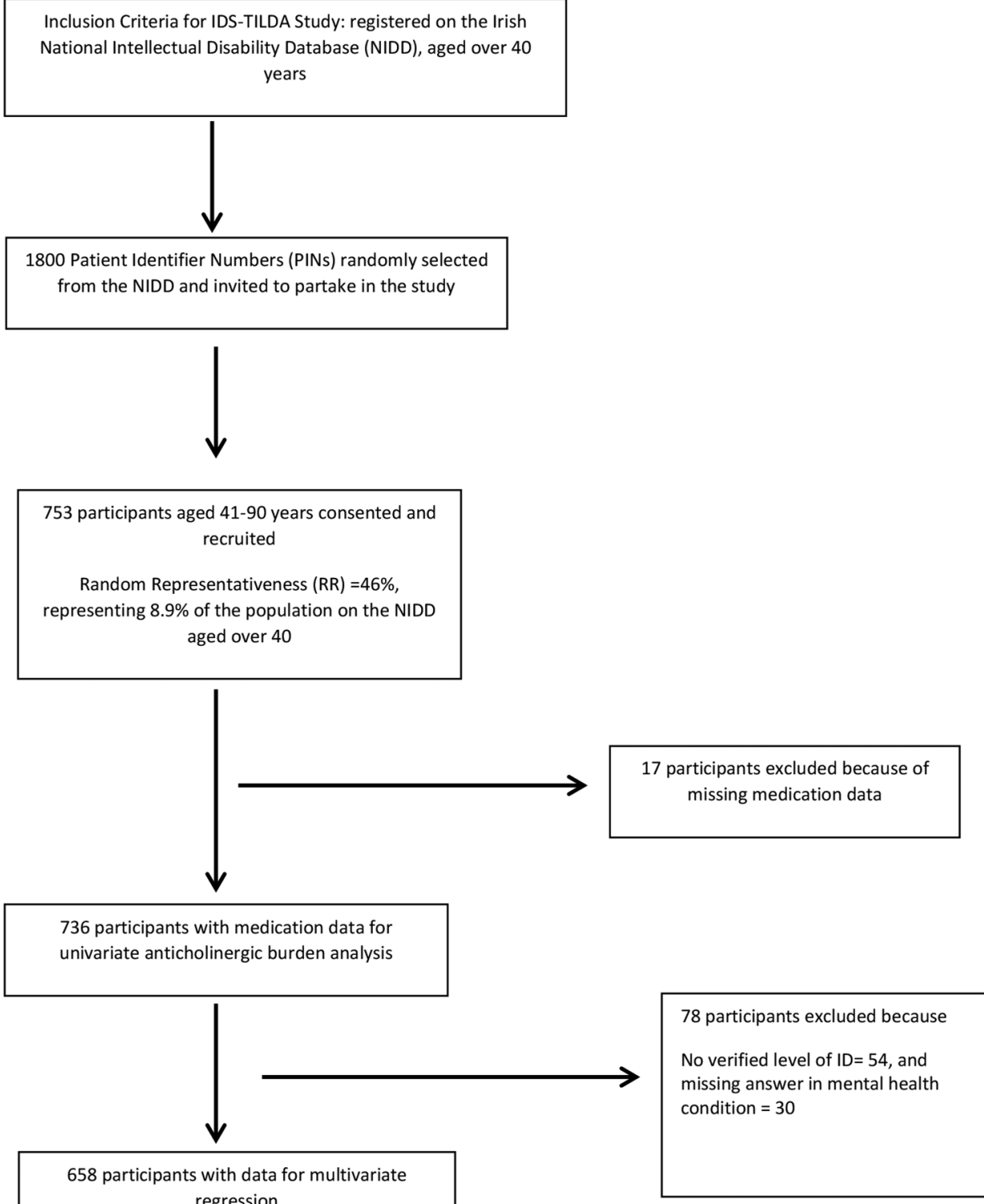

Medication data was then confirmed by the interviewers at the time of interview.

Medicines and supplements were recorded using the WHO Anatomical Therapeutic Chemical Classification (ATC) classification code, International Non-Proprietary name (INN name), and brand name where available. ${ }^{24}$ Two pharmacists (MO and JP) independently reviewed the original hard copy preinterview questionnaires and confirmed entries into the dataset and classified all use of medications. Information on the duration or of the cost of prescription was not collected.

\section{Medicine definition}

Medication use was defined as regular use (every day or every week); this included oral, parenteral, topical, and ophthalmological and inhaled medicinal products. Concurrent use was defined as the regular use of at least two medications. ${ }^{25}$
We defined a food supplement according to the Directive 2002/46/EC of the European Parliament and of the Council, of 10 June 2002. ${ }^{26}$ Food supplements herbal medicines, and homeopathic medicines were excluded from the definition of a medicine.

Certain medicines were reclassed according to their indications and previously reported classes in other pharmacoepidemiological studies:

- Rectal diazepam (N05BA01) and buccal midazolam (NO5CD08) were categorised as 'medicines used to treat acute seizures' as per their Summary of Product Characteristics indications.

- Lithium (N05AN01) was reclassified as a mood stabiliser.

- Clobazam was reclassified as an antiepileptic

- Prochlorperazine was included in the antiemetic/ antinauseant grouping (A04), as sufficient dosing data was available to suggest that it was primarily 
being used in low doses $(5-10 \mathrm{mg})$ as licensed for Meniere's syndrome or nausea and vomiting in Ireland rather than $75-100 \mathrm{mg}$ indicated in psychosis.

\section{Polypharmacy definition}

The primary outcome of interest (the dependent variable) was whether a participant was exposed to no polypharmacy, polypharmacy or excessive polypharmacy.

There is no universally agreed definition of polypharmacy; however, we drew on published studies. ${ }^{27-29}$

- Excessive polypharmacy (EPP): concurrent use of ten or more different drugs.

- Polypharmacy (PP): the use of five to nine drugs.

- No polypharmacy: taking four or less drugs (included those taking no medicines).

\section{Chronic health conditions}

Each participant/caregiver respondent reported if the individual with ID had ever been diagnosed by a doctor/ relevant health professional with one or more of 12 chronic health conditions. ${ }^{10}$ Multimorbidity was defined as the co-occurrence of two or more of these chronic health conditions in one person. ${ }^{30}$ For the purposes of further detailed analysis in our study, lung disease, liver disease, stroke and cancer were not included in further analysis, as each had a prevalence of $<5 \%$ in the sample.

\section{Pain}

Pain was measured using response to the question 'Are you often troubled with pain?' ( $n=714)$.

\section{Health care utilisation}

Participants were asked in the preinterview questionnaire the number of occasions in the previous year they had accessed a range of primary, secondary and tertiary care services including GP, outpatient, accident and emergency (A\&E) admissions and nights in hospital.

\section{Statistical analysis}

Statistical analyses were carried out using the Statistical Package for Social Sciences, V.20.0 (SPSS Inc). The characteristics of the eligible sample were expressed as percentages, medians with SDs $( \pm \mathrm{SD})$ and $95 \%$ CIs. The overall prevalence of no polypharmacy, polypharmacy and excessive polypharmacy exposure was calculated as a proportion of the total eligible population $(n=736)$. A $\chi^{2}$ test for independence at univariate level was used to test for a significant association between the three polypharmacy groupings. For continuous variables, a one-way analysis of variance (ANOVA) was used to test for a significant difference. Univariate analysis was initially used to examine associations between the dependant (polypharmacy exposure) and explanatory variables.

Multinomial logistic regression was performed to identify clinical and demographic factors associated with polypharmacy and excessive polypharmacy exposure. In this model, the outcome (dependent) variable had three possible outcomes and the individuals who reported no polypharmacy exposure (0-4 medicines) were the reference category. All demographic variables were included in the multivariate model (age, gender, level of ID). Those who lived independently or in community group homes were included as a single variable, as the subpopulation of those reporting excessive polypharmacy in the independent setting was small $(n=5)$. Only those with verified ID $(n=682)$ were included in regression analyses. Clinical variables with a significance of $p<0.10$ at bivariate level were selected for inclusion in the multivariate model (this $\mathrm{p}$ value was selected so that important or influential factors were not omitted). Multicollinearity between independent variables was examined using a variance inflation factor (VIF), >2 being the cut-off. ${ }^{31}$ All fell below the specified threshold. Variables were entered into the multivariate model simultaneously. Results are presented as ORs with corresponding 95\% CIs. Interpretation of the results for a specific risk factor is based on the odds of being, for example, exposed to excessive polypharmacy rather than being exposed to no polypharmacy. Significance is assumed at $p$ value $<0.05$.

\section{Sample size and power}

Sample size calculation for the logistic regression was based on the guideline of Peduzzi et al $;{ }^{32}$ for a minimum number of cases $(\mathrm{N})$ needed for the study; $\mathrm{N}=10 \mathrm{k} / \mathrm{p}$, where $p$ is the smallest of the proportions of negative or positive cases in the population, $\mathrm{k}$ the number of covariates (independent variables) and $\mathrm{k} / \mathrm{p}$ is the number of events per variable (EPV). For our regression model, there were 12 covariates and the proportion of negative cases (excessive polypharmacy) was 0.215 , therefore a minimum sample size $(\mathrm{N})$ of 558 was needed. There were 653 cases available for regression analyses, so sample size was sufficient.

\section{RESULTS}

\section{Demographics and chronic conditions}

Table 1 includes details of the demographic and clinical characteristics of the eligible sample with medication data $(\mathrm{n}=736)$. Mean age of participants was 54.1 years (SD 8.8, range 41-90 years), with almost half (45.7\%) aged between 50 and 64 years. Almost half $(46 \%)$ with recorded level of ID ( $n=682)$ reported moderate ID.

The four most frequently reported chronic conditions were: eye $(51.3 \%)$, mental health $(47.7 \%)$, neurological (36.3\%, of which $30.7 \%$ had epilepsy) and gastrointestinal $(26.7 \%)$, with $71 \%$ reporting multimorbidity.

\section{Drug use}

Almost all $(92.4 \% ; 680)$, reported taking one or more medicines, with a maximum of 19 , a mean $( \pm$ SD) of 5.7 $( \pm 4.4)$ medicines. Of this, almost a half $(46.3 \%)$ took fewer than five drugs with polypharmacy $(32.2 \%)$, more common than excessive polypharmacy $(21.5 \%)$. Gender 
Table 1 Demographic and clinical characteristics of the population $(n=736)$

\begin{tabular}{|c|c|c|c|}
\hline Characteristic & n (\%) 736 & Male 330 & Female 406 \\
\hline \multicolumn{4}{|l|}{ Age (years) } \\
\hline $40-49$ & $266(36.1)$ & $133(40.3)$ & $133(32.8)$ \\
\hline $50-64$ & $336(45.7)$ & $139(42.1)$ & $197(48.5)$ \\
\hline $65+$ & $134(18.2)$ & $58(17.6)$ & $76(18.7)$ \\
\hline \multicolumn{4}{|l|}{ Level of ID $(n=682)$} \\
\hline Mild & 166 (23.9) & $70(23.0)$ & $93(24.6)$ \\
\hline Moderate & $323(46.5)$ & 139 (45.7) & $177(46.8)$ \\
\hline Severe & $168(24.2)$ & 76 (25.0) & $91(24.1)$ \\
\hline Profound & $37(5.3)$ & $19(6.2)$ & $17(4.5)$ \\
\hline \multicolumn{4}{|l|}{ Residential setting } \\
\hline Independent & $122(16.6)$ & $58(17.6)$ & $64(15.8)$ \\
\hline Community group home & $265(36.0)$ & $121(36.7)$ & $144(35.5)$ \\
\hline Residential & $349(47.4)$ & $151(45.8)$ & $198(48.8)$ \\
\hline \multicolumn{4}{|l|}{ BMI category $(n=574)$} \\
\hline Underweight $(\mathrm{BMI}<18.5)$ & $12(2.1)$ & $6(2.2)$ & $6(1.9)$ \\
\hline Normal weight (18.5-24.99) & $214(37.2)$ & $108(40.1)$ & $109(34.8)$ \\
\hline Overweight (25-29.99) & $173(30.1)$ & 90 (33.5) & $84(26.8)$ \\
\hline Obese $(\geq 30)$ & $175(30.4)$ & $65(24.2)$ & $114(36.4)$ \\
\hline Mean $( \pm S D)$ conditions & $2.5( \pm 1.5)$ & $2.2( \pm 1.5)$ & $2.7( \pm 1.5)$ \\
\hline
\end{tabular}

was not an association but excessive polypharmacy increased with age.

The level of ID was significantly associated $(\mathrm{p}<0.001$, $\mathrm{n}=682$ ) with polypharmacy and excessive polypharmacy; $47.3 \%$ of those with polypharmacy had severe/profound ID and almost one-third $(29.3 \%)$ of those with severe/ profound ID reported excessive polypharmacy (table 2). In contrast, $<5 \%$ of those living independently reported excessive polypharmacy $(\mathrm{p}<0.001, \mathrm{n}=736)$.

\section{Therapeutic drug classes and reported conditions}

The frequency of prescribing corresponded to the frequency of reported chronic conditions (table 3). Six of the most frequently reported therapeutic classes were drugs for mental health conditions and epilepsy (table 3). Almost two-thirds $(64.6 \%)$ of the excessive polypharmacy group and over half $(54.9 \%)$ of those with polypharmacy reported one or more antipsychotics, compared with $26 \%$ with no polypharmacy. Antiepileptics were the second most frequently reported class $(39 \%)$ and represented $63.1 \%$ of the excessive polypharmacy, $54 \%$ of the polypharmacy but only $16.7 \%$ of the no polypharmacy groups. Of the 287 participants who reported antiepileptic medications, $71.4 \%$ (205) reported a diagnosis of epilepsy while the majority of the other 82 participants $(n=65 ; 78.8 \%)$ had a doctor's diagnosis of an emotional/nervous or psychiatric condition. The increase in use of a drug class across the groups was greatest for anxiolytics with 16 times as many users in the excessive polypharmacy group compared with the no polypharmacy group. This contrasted with only 2.5 times as many reporting an antipsychotic, emphasising the high usage across all groups and the reported prevalence of mental ill health.
Laxatives $(75.3 \%)$ and drugs for peptic ulcer disease (PUD)/gastro-oesophageal reflux disease (GORD) $(49 \%)$ were frequently reported by the excessive polypharmacy group but were reported by only $12.3 \%$ and $8.8 \%$, respectively, of the no polypharmacy group. Proton pump inhibitors were the principal drugs in this group reported by $21.7 \%$ of all participants and $44.5 \%$ of those in the excessive polypharmacy group. Of the sample, $43 \%$ reported that constipation was a problem, and almost one-fifth reported a doctor's diagnosis of chronic constipation.

Lipid modifying agents (25.4\%) were the most frequently reported cardiovascular agents with a notably lower reported use of other cardiovascular agents; antithrombotics $(10.6 \%)$, agents acting on the reninangiotensin system $(6.5 \%)$. Thyroid disease and drugs were frequently reported and varied little across the groups and were around threefold greater than the number reporting diabetes and receiving antidiabetic drugs.

Of those who answered the question (714), 334 reported experiencing pain. Of the analgesics reported, paracetamol was most frequently used; $34.2 \%$ overall, with infrequent use of more potent analgesics-2.3\% of reporting use of paracetamol/codeine combinations, and $0.8 \%$ reporting use of opioids. Non-steroidal antiinflammatory drugs (NSAIDs) were less frequently used —oral and topical-by $9.9 \%$ of participants.

Eye conditions were the most commonly reported conditions in the cohort, with half of participants reporting an eye condition. ${ }^{10}$ Prevalence of use of eye preparations was low; $2.8 \%$ reported lubricant preparations (ATC $\mathrm{S} 01 \mathrm{X}$ ), and $1.1 \%$ reported antiglaucoma and miotic preparations and $2.8 \%$ (10) a diagnosis of glaucoma. 
Table 2 Bivariate associations between explanatory variables and polypharmacy status $(n=736)$

\begin{tabular}{|c|c|c|c|c|c|}
\hline Characteristic & $\begin{array}{l}\text { Total } \\
\text { population } \\
\text { n (\%) }\end{array}$ & $\begin{array}{l}\text { No polypharmacy } \\
\text { (0-4 drugs) n (\%) }\end{array}$ & $\begin{array}{l}\text { Polypharmacy } \\
\text { (5-9 drugs) n (\%) }\end{array}$ & $\begin{array}{l}\text { Excessive } \\
\text { polypharmacy } \\
(\geq 10 \text { drugs) } n(\%)\end{array}$ & p Value \\
\hline & 736 & 341 & 237 & 158 & \\
\hline \multicolumn{6}{|l|}{ Demographics } \\
\hline \multicolumn{6}{|l|}{ Gender } \\
\hline Male & 330 & $163(49.4)$ & $101(30.6)$ & $66(20.0)$ & 0.334 \\
\hline Female & 406 & $178(43.8)$ & $136(33.5)$ & $92(22.7)$ & \\
\hline \multicolumn{6}{|l|}{ Age group (years) } \\
\hline $40-49$ & 266 & $142(53.4)$ & $74(27.8)$ & $50(18.8)$ & $<0.001$ \\
\hline $50-64$ & 336 & $160(47.6)$ & $113(33.6)$ & $63(18.8)$ & \\
\hline$\geq 65$ & 134 & $39(29.1)$ & $50(37.3)$ & $45(33.5)$ & \\
\hline Level of ID $(n=682)$ & & & & & $<0.001$ \\
\hline Mild & 163 & $100(61.3)$ & $35(22.1)$ & $28(17.2)$ & \\
\hline Moderate & 316 & $161(50.9)$ & $93(29.4)$ & $62(19.6)$ & \\
\hline Severe/profound & 203 & $47(23.1)$ & 96 (47.3) & $60(29.6)$ & \\
\hline Residential setting & & & & & $<0.001$ \\
\hline Independent & 122 & $106(86.8)$ & $18(14.8)$ & $5(4.1)$ & \\
\hline Community group home & 265 & $151(57.0)$ & $83(31.3)$ & $33(12.5)$ & \\
\hline Residential institution & 349 & $100(28.7)$ & $136(39.0)$ & $120(34.4)$ & \\
\hline Drug use (mean $\pm S D)$ & $5.8( \pm 4.4)$ & $2.1 \pm 1.4$ & $6.7 \pm 1.5$ & $12.6 \pm 2.4$ & $<0.001$ \\
\hline \multicolumn{6}{|l|}{ Chronic diseases } \\
\hline Eye condition* & $380(51.6)$ & $265(69.7)$ & $111(29.2)$ & 74 (19.5) & 0.032 \\
\hline Mental health & $356(48.0)$ & 103 (28.9) & 142 (39.9) & $111(31.2)$ & $<0.001$ \\
\hline Neurological & $268(35.0)$ & $70(26.4)$ & $110(41.0)$ & $88(32.9)$ & $<0.001$ \\
\hline Gastrointestinal & $198(26.9)$ & $50(25.2)$ & $71(35.9)$ & 77 (38.9) & $<0.001$ \\
\hline Joint disease & $153(20.8)$ & $50(32.7)$ & $59(38.6)$ & $44(28.8)$ & $<0.001$ \\
\hline Endocrine disease & $162(22.0)$ & $57(35.2)$ & $56(34.6)$ & $49(30.2)$ & $<0.001$ \\
\hline Hypertension & $112(15.2)$ & $32(28.6)$ & $42(37.5)$ & 38 (33.9) & $<0.001$ \\
\hline Heart disease & $89(12.1)$ & $32(36.0)$ & $30(33.7)$ & $27(30.3)$ & 0.024 \\
\hline Reported pain $(n=714)$ & 334 & $83(24.9)$ & $82(24.6)$ & $73(21.8)$ & $<0.001$ \\
\hline
\end{tabular}

\section{Factors associated with polypharmacy and excessive polypharmacy}

Results from the multinomial logistic regression are presented in table 4. Living in a residential institution, and reporting having a mental health, neurological, endocrine condition or hypertension were each independently associated with polypharmacy and excessive polypharmacy exposure at both levels, controlling for all other factors in the model. Those with severe/profound ID were likely to be exposed to polypharmacy, but not excessive polypharmacy. Gastrointestinal disease was significantly associated with excessive polypharmacy only. Gender, age, eye conditions, heart disease or joint disease were not significantly associated with polypharmacy or excessive polypharmacy.

\section{Therapeutic classes, residential setting}

A greater proportion of participants living in residential institutions reported use of antipsychotics, antiepileptics and laxatives compared to those living independently or in community group homes $(\mathrm{p}<0.001)$ (figure 2$)$.

\section{Intraclass polypharmacy}

Intraclass polypharmacy was observed in the three most frequent therapeutic classes; of those who reported antipsychotics (319), one-quarter $(25.7 \%)$ received antipsychotic polytherapy and $39.7 \% \quad(n=114)$ of those with antiepileptic drug (AED) use reported antiepileptic polytherapy while almost half, $47 \% \quad(n=130)$, of those with laxative use reported laxative polytherapy. Of those reporting laxative polytherapy, half $(50.8 \%)$ reported a doctor's diagnosis of chronic constipation.

\section{Healthcare utilisation}

There was a significant bivariate association $(\mathrm{p}<0.001)$, between the number of GP consultations and outpatient visits in the previous year and polypharmacy status (table 5). Over $40 \%$ of the sample reported six or more GP consultations in the previous year. Similarly, nearly $30 \%$ of the excessive polypharmacy group spent one or more nights in hospital compared with $<8 \%$ of those with no polypharmacy $(\mathrm{p}=0.002)$.

\section{DISCUSSION}

\section{Principal findings}

Almost everyone in this cohort of people with ID of 40 years and older were taking medicines-polypharmacy was the norm and excessive polypharmacy was common. The burden of multimorbidity was also high 
Table 3 Proportions of drug users in the therapeutic classes reported by $>5 \%$ of the sample $(n=736)$

\begin{tabular}{|c|c|c|c|c|c|}
\hline & $\begin{array}{l}\text { ATC } \\
\text { code }\end{array}$ & $\begin{array}{l}\text { Total } \\
\text { population } \\
736 \mathrm{n}(\%)\end{array}$ & $\begin{array}{l}\text { No polypharmacy } \\
\text { (0-4 drugs) } \\
341 \mathrm{n}(\%)\end{array}$ & $\begin{array}{l}\text { Polypharmacy } \\
\text { (5-9 drugs) } \\
237 \text { n (\%) }\end{array}$ & $\begin{array}{l}\text { Excessive } \\
\text { polypharmacy } \\
\text { ( } \geq 10 \text { drugs) } 158 \mathrm{n}(\%)\end{array}$ \\
\hline Antipsychotics & N05A & 319 (43.2) & $89(26.1)$ & $128(54.0)$ & $102(64.6)$ \\
\hline Antiepileptics† & N03A & $287(39.0)$ & $60(17.6)$ & $128(54.1)$ & $99(63.1)$ \\
\hline Laxatives & $\mathrm{A} 06 \mathrm{~A}$ & $278(37.8)$ & $42(12.3)$ & $117(49.4)$ & $119(75.3)$ \\
\hline Analgesics & N02B & 277 (37.6) & $52(15.2)$ & $107(45.1)$ & $118(75.1)$ \\
\hline Antidepressants $†$ & N06C & $193(26.2)$ & $51(15.0)$ & $83(35.0)$ & $69(43.7)$ \\
\hline Anxiolytics† & N05B & $173(23.5)$ & $24(7.0)$ & $70(29.5)$ & $79(50.0)$ \\
\hline Lipid modifying agents & C10A & $187(25.4)$ & $69(20.2)$ & $62(26.2)$ & $56(35.7)$ \\
\hline Drugs for PUD/GORD & A02B & $177(24.0)$ & $30(8.8)$ & $70(29.5)$ & $77(49.0)$ \\
\hline Drugs for thyroid conditions & $\mathrm{H} 03 \mathrm{~A}$ & $132(17.9)$ & $49(14.4)$ & $48(20.3)$ & $35(22.3)$ \\
\hline Anticholinergic agents Preparations & N04A & $120(16.3)$ & $14(4.1)$ & $53(22.3)$ & $53(33.8)$ \\
\hline Hynotics and sedatives $†$ & N05C & $100(13.6)$ & $6(2.1)$ & $40(16.9)$ & $54(34.2)$ \\
\hline Antithrombotics & B01A & 78 (10.6) & $11(3.2)$ & $37(15.6)$ & $30(19.1)$ \\
\hline NSAID drugs & M01A & $73(9.9)$ & $12(3.5)$ & $25(10.5)$ & $36(22.9)$ \\
\hline Antipropulsives & A07D & $68(9.2)$ & $5(1.4)$ & $20(8.4)$ & $43(27.3)$ \\
\hline Antihistamines & $\mathrm{R} 06 \mathrm{~A}$ & $65(8.8)$ & $10(2.9)$ & $25(10.5)$ & $30(19.1)$ \\
\hline Drugs affecting bone & M05B & $59(8.0)$ & $11(3.2)$ & $22(8.4)$ & $26(16.6)$ \\
\hline Propulsives & $\mathrm{A03F}$ & $56(7.6)$ & $1(0.3)$ & $20(8.4)$ & 35 (22.3) \\
\hline Inhaled adrenergics & R03A & $53(7.0)$ & $5(1.5)$ & $17(7.2)$ & $31(19.7)$ \\
\hline Expectorants & $\mathrm{R} 05 \mathrm{C}$ & $51(6.9)$ & $4(1.2)$ & $16(6.8)$ & $31(19.7)$ \\
\hline $\begin{array}{l}\text { Agents acting on the renin- } \\
\text { angiotensin system }\end{array}$ & C09A & $48(6.5)$ & $9(2.6)$ & $18(7.6)$ & $21(13.4)$ \\
\hline Oral antidiabetics & $\mathrm{A} 10 \mathrm{~B}$ & $41(5.6)$ & $6(1.8)$ & $18(7.6)$ & $17(10.8)$ \\
\hline \multicolumn{6}{|c|}{$\begin{array}{l}\text { Other therapeutic classes reported by }<5 \% \text { in decreasing prevalence; selective calcium-channel blockers (C08C), } \beta \text {-blocking agents (C07A), } \\
\text { Antifungals for topical use (D01A), other drugs for obstructive airway disease, inhalants (R03B), antiemetics and antinauseants (A04A), other } \\
\text { ophthalmologicals (S01X), other systemic drugs for obstructive airways (R03D). } \\
\text { †Modifications described in methods. } \\
\text { GORD, gastro-oesophageal reflux disease; NSAID, non-steroidal anti-inflammatory drug; PUD, peptic ulcer disease. }\end{array}$} \\
\hline
\end{tabular}

with participants reporting a mean of 2.5 chronic conditions. However, after adjusting for confounding factors, it was those with mental health conditions, gastrointestinal conditions, neurological conditions, endocrine disease and hypertension that were more likely to be exposed to polypharmacy and excessive polypharmacy, whereas neither age nor gender had any significant influence. Corresponding to this, we found a high prevalence of agents used to treat epilepsy, mental health and gastrointestinal conditions, and a substantial but lesser use of drugs for thyroid disease. Use of analgesics, particularly paracetamol, was common and similarly the prevalence of pain was associated with polypharmacy and excessive polypharmacy. More frequent healthcare utilisation, with the exception of Emergency Department visits, was also associated with the degree of polypharmacy. Notably, we identified that the only association between polypharmacy status and the level of ID was between those with severe/profound ID and polypharmacy alone, whereas, by contrast, those living in residential institutions were more likely to be exposed to polypharmacy and excessive polypharmacy independently of other factors. In parallel, there was also an increasing gradient of use of antipsychotics, antiepileptics and laxatives with an increasing degree of supervision. Moreover, intraclass polypharmacy was only notable among the three most frequently prescribed therapeutic groups; antispychotics, antieplieptics and laxatives.

\section{Strengths and weaknesses of the current study}

This study has a number of key strengths. First, it is a comprehensive examination of the patterns and factors associated with polypharmacy and excessive polypharmacy in a representative older population with ID. The use of the two thresholds for multiple medicine use (ie, polypharmacy and excessive polypharmacy) have not been utilised before in ID population and the threshold of 10 or more indicates greater risk. ${ }^{33}$ The sample benefits from the representativeness of the national ID population in Ireland from which it was drawn meaning that these findings have the potential to be generalised to other populations with ID, and was sufficiently large that our multivariate analysis had sufficient power. The great majority of respondents recorded medication data $(98 \%)$, and detailed collection of medication use allowed for accurate cross-sectional capture of medicines a participant was taking, including over-the-counter medicines. Participants and/or proxy respondents completed a detailed assessment of health characteristics, permitting examination of potential confounders in the regression model. While we cannot rule out other residual confounding, in our multivariate analysis we 
Table 4 Factors associated with pharmacy and polypharmacy, multinomial logistic regression $(n=658)$

\begin{tabular}{|c|c|c|c|c|}
\hline \multirow[b]{3}{*}{ Characteristic } & \multicolumn{4}{|c|}{ Polypharmacy categories } \\
\hline & \multicolumn{2}{|c|}{ Polypharmacy (5-9 medicines) } & \multicolumn{2}{|c|}{$\begin{array}{l}\text { Excessive polypharmacy } \\
\text { (10+ medicines) }\end{array}$} \\
\hline & OR (95\% Cl) & p Value & OR $(95 \% \mathrm{Cl})$ & p Value \\
\hline \multicolumn{5}{|l|}{ Gender } \\
\hline Male & 1.00 & & 1.00 & \\
\hline Female & $0.95(0.62-1.45)$ & 0.81 & $0.93(0.55-1.56)$ & 0.78 \\
\hline \multicolumn{5}{|l|}{ Age (years) } \\
\hline $40-49$ & 1.00 & & 1.00 & \\
\hline $50-64$ & $1.12(0.71-1.77)$ & 0.64 & $0.75(0.43-1.34)$ & 0.33 \\
\hline $65+$ & $1.63(0.87-3.07)$ & 0.13 & $1.79(0.87-3.68)$ & 0.12 \\
\hline \multicolumn{5}{|l|}{ Level of ID } \\
\hline Mild & 1.00 & & 1.00 & \\
\hline Moderate & $1.34(0.79-2.30$ & 0.77 & $0.77(0.39-1.51$ & 0.45 \\
\hline Severe/profound & $4.06(2.08-7.91$ & $<0.001$ & $1.38(0.62-3.10$ & 0.43 \\
\hline \multicolumn{5}{|l|}{ Residence } \\
\hline Independent/community group home & 1.00 & & 1.00 & \\
\hline Residential institution & $2.08(1.33-3.25)$ & 0.001 & $6.90(3.88-12.25)$ & $<0.001$ \\
\hline \multicolumn{5}{|l|}{ Conditions } \\
\hline \multicolumn{5}{|l|}{ Mental health } \\
\hline No & 1.00 & & 1.00 & \\
\hline Yes & $3.98(2.59-6.11)$ & $<0.001$ & $6.05(3.55-10.31)$ & $<0.001$ \\
\hline \multicolumn{5}{|l|}{ Neurological } \\
\hline No & 1.00 & & 1.00 & \\
\hline Yes & $3.67(2.32-5.80)$ & $<0.001$ & $6.08(3.51-10.53)$ & $<0.001$ \\
\hline \multicolumn{5}{|l|}{ Gastrointestinal disease } \\
\hline No & 1.00 & & 1.00 & \\
\hline Yes & $1.10(0.66-1.84)$ & 0.73 & $2.66(1.51-4.67)$ & 0.001 \\
\hline \multicolumn{5}{|l|}{ Joint disease } \\
\hline No & 1.00 & & 1.00 & \\
\hline Yes & $1.52(0.89-2.58)$ & 0.12 & $1.33(0.71-2.51)$ & 0.37 \\
\hline \multicolumn{5}{|l|}{ Endocrine disease } \\
\hline No & 1.00 & & 1.00 & \\
\hline Yes & $2.06(1.23-3.47)$ & 0.006 & $3.69(2.00-6.80)$ & $<0.001$ \\
\hline \multicolumn{5}{|l|}{ Eye condition } \\
\hline No & 1.00 & & 1.00 & \\
\hline Yes & $0.67(0.44-1.00)$ & 0.05 & $0.68(0.39-1.17)$ & 0.17 \\
\hline \multicolumn{5}{|l|}{ Hypertension } \\
\hline No & 1.00 & & 1.00 & \\
\hline Yes & $3.09(1.65-5.80)$ & $<0.001$ & $3.68(1.78-7.63)$ & $<0.001$ \\
\hline \multicolumn{5}{|l|}{ Heart disease } \\
\hline No & 1.00 & & 1.00 & \\
\hline Yes & $1.20(0.63-2.31)$ & 0.58 & $1.51(0.71-3.22)$ & 0.28 \\
\hline
\end{tabular}

took into account demographic and other clinical potential confounders.

There are a number of methodological limitations to be considered. Chronic conditions and medication use reported was based on participant or proxy self-report, and thus may be liable to a misclassification bias. ${ }^{35}$ However, the information gathered in the preinterview questionnaire (PIQ) was cross-checked at the time of interview and participants were given sufficient time before the PIQ was returned to gather the information. Such verification of information at the time of interview provides greater reliability than self-report recall methods alone. ${ }^{25}$
We do not know the extent to which answers in the face-to-face interview may have been influenced by the combination of responses styles. Those with severe or profound ID were more likely to have a proxy-only interview or a mixed answer style which enabled non-verbal participants, or those with severe ID to partake.

Strengths and weaknesses in relation to other studies, discussing important differences in results

In so far as they are comparable, the results of this study are similar to those of two other recent ID cohorts. ${ }^{36} 37$ In Australia, in 2008, a survey of 897 people with ID in 
Figure 2 Proportion of participants receiving three most frequently reported therapeutic classes according to residential status $(n=736)$.

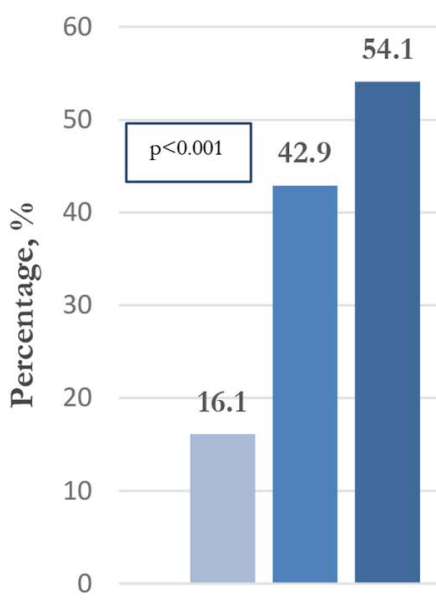

Antipsychotics

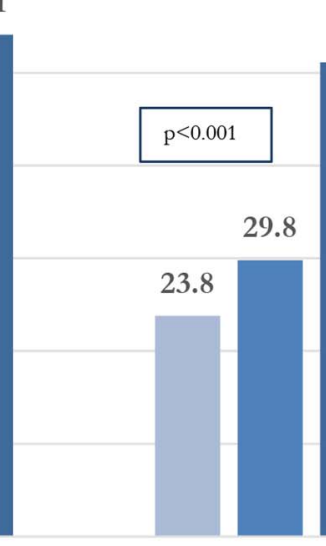

Antiepileptics
51.1

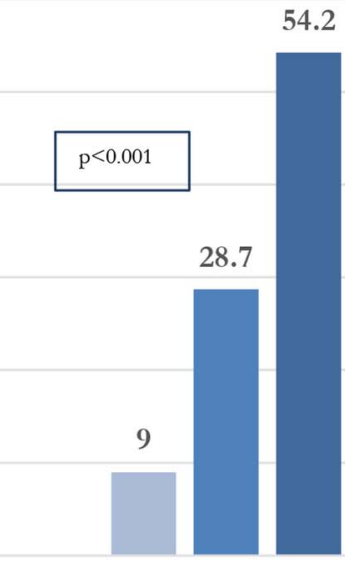

Laxatives

Therapeutic Class

\section{Independent $\quad$ Community Group Home $\quad$ Residential}

the state of Victoria aged from $18-82$ years, a community dwelling population with ID who had used health services and reported that $27.8 \%$ of those over 40 years of age and $41.7 \%$ of the over 60 s used over five medicines, ${ }^{36}$ while in Canada, in 2009, among 52404 adults aged 18-64 years with developmental disabilities using the Ontario Disability Support Group, 37.1\% of those aged $45-54$ years and $42.1 \%$ of those aged 55-64 years received five or more medicines. ${ }^{37}$ In our study, those living independently or in community group homes are probably most similar to these cohorts and the prevalence of polypharmacy among the two subgroups combined was $35.1 \%$.
Prevalence of polypharmacy and excessive polypharmacy in older people with ID in this study is far higher than rates reported for a coincident cohort of the general Irish population over 50 years, where rates of $19 \%$ and $2 \%$ respectively were reported. ${ }^{29}$ In other older community dwelling non-ID populations, where the same definition of polypharmacy has been used, prevalence rates of polypharmacy ranging from $4 \%$ to $42 \%$ have been reported. ${ }^{38} 3940$ In a Dutch National Survey of General Practice in 2001, 712 individuals with ID received over three times as many repeat prescriptions compared with controls without ID (matched on age, sex and general practice). ${ }^{41}$

\begin{tabular}{|c|c|c|c|c|c|}
\hline Characteristic & $\begin{array}{l}\text { Total } \\
\text { population } \\
\text { n (\%) }\end{array}$ & $\begin{array}{l}\text { No polypharmacy } \\
\text { (0-4 drugs) n (\%) }\end{array}$ & $\begin{array}{l}\text { Polypharmacy } \\
\text { (5-9 drugs) n (\%) }\end{array}$ & $\begin{array}{l}\text { Excessive } \\
\text { polypharmacy } \\
\text { ( } \geq 10 \text { drugs) } n(\%)\end{array}$ & p Value* \\
\hline & 736 & 341 & 257 & 158 & \\
\hline \multicolumn{6}{|c|}{ Healthcare utilization } \\
\hline \multicolumn{6}{|c|}{ Primary care } \\
\hline \multicolumn{6}{|c|}{ Number of GP consultations in previous year $(n=644)$} \\
\hline $0-1$ visits & $90(14.0)$ & $64(21.3)$ & $16(6.2)$ & $10(6.3)$ & \multirow[t]{3}{*}{$<0.001$} \\
\hline $2-5$ visits & $272(42.2)$ & $146(48.5)$ & $86(40.2)$ & $40(31.0)$ & \\
\hline $6+$ & $282(43.8)$ & 91 (30.3) & $112(52.3)$ & $79(61.2)$ & \\
\hline \multicolumn{6}{|c|}{ Secondary and tertiary care } \\
\hline \multicolumn{6}{|c|}{ Number of outpatient visits in previous year $(n=678)$} \\
\hline 0 visits & $339(50.0)$ & $187(59.7)$ & $105(47.7)$ & $47(32.4)$ & \multirow[t]{3}{*}{$<0.001$} \\
\hline 1 visit & $117(17.3)$ & $45(14.4)$ & 46 (20.9) & $26(17.9)$ & \\
\hline $2+$ visits & $222(32.7)$ & $81(25.9)$ & 69 (31.4) & $72(49.6)$ & \\
\hline \multicolumn{6}{|c|}{ Number of $A \& E$ visits in previous year $(n=700)$} \\
\hline 0 visits & $567(81.0)$ & $273(83.7)$ & $179(79.2)$ & $115(77.7)$ & 0.21 \\
\hline $1+$ visit & $133(19.0)$ & 53 (16.3) & 47 (20.8) & 33 (22.3) & 0.002 \\
\hline \multicolumn{6}{|c|}{ Number of nights in general hospital in previous year $(n=688)$} \\
\hline 0 nights & $610(91.1)$ & $293(92.4)$ & $200(88.1)$ & $117(81.3)$ & \\
\hline $1+$ night & $78(8.9)$ & $24(7.6)$ & 27 (11.9) & $27(28.7)$ & \\
\hline
\end{tabular}


Our multivariate analysis found no significant association between polypharmacy exposure and gender; a finding which is consistent with some previous ID studies; ${ }^{36}{ }^{42}$ however, Cobigo reported that a greater proportion of women were prescribed five or more medicines at univariate level. ${ }^{37}$ We also found that age was not a factor and this differs from Haider et $a l^{66}$ who identified that older age was associated with polypharmacy exposure although their cohort included individuals aged 18-39 year (54.3\%), and this subgroup was taken as the reference group for their model. Moreover, although Haider and coworkers took account of sex and severity of ID, they could not adjust for clinical conditions. Cobigo reported at univariate level that older adults with ID reported a greater number of medicines, but unlike this study she did not include people over the age of $65 .^{37}$

In the non-ID elderly population, women are more likely to report polypharmacy across all age groups ${ }^{38} 3943$ and increasing age has been consistently identified as a key determinant of polypharmacy exposure. ${ }^{44-46}$

\section{Meaning of the study: possible explanations and implications for clinicians and policymakers}

One possible explanation for the differences between our findings and those in some ID and all the non-ID studies may be the earlier onset of disease and the presence of long standing comorbidities such as epilepsy, mental health and gastrointestinal conditions, which are equally associated with both sexes and result in older people with ID being exposed to increasing number of medicines at younger ages with a lesser increase after 50 years of age. This contention is supported by the Ontario study that showed polypharmacy was seven times higher in the 55-64 age group compared with those aged between 18 and 24 years ${ }^{37}$ and by a small Australian study that showed those over 47 years of age took more psychotropics compared with groups from 25 to 46 years of age. ${ }^{47}$

Increased healthcare utilisation, including GP visits, was associated with polypharmacy and excessive polypharmacy. This may reflect the intensity of monitoring and management that is required as the Dutch National Survey of General Practice also found an increased consultation rate among people with ID compared with matched controls. ${ }^{41}$

Multivariate analysis revealed that place of residence was associated with polypharmacy exposure, with those living in residential institutions being much more likely to be exposed to polypharmacy and excessive polypharmacy. These findings are consistent with several studies in the ID population where greater medicine use, in particular, psychotropic drug use has been reported in institutional settings, ${ }^{16}{ }^{48}$ however, unlike the present study demographic and clinical variables were not controlled for in those analyses. Furthermore, we also found that severe/profound ID was associated only with polypharmacy and not excessive polypharmacy while other studies have reported contrasting ${ }^{36}$ and similar findings. ${ }^{49}$ Since a greater proportion of those with severe ID live in residential care, this was unexpected and raises the possibility that the influence of the institution on the provision of care is substantial. Each of the three most frequently recorded drug groups, antipsychotics, antiepileptics and laxatives, were all more frequently reported by those in residential, as compared to community group homes or those living independently. Vetrano et a $\tilde{D}^{0}$ found that $16.9 \%$ of elderly, cognitively impaired nursing home residents from seven European countries were exposed to excessive polypharmacy with laxatives, proton pump inhibitors and antipsychotics among the most frequently prescribed drugs. The influence of place of residence on the degree and pattern of medication use is of particular relevance in Ireland, as there are renewed efforts to move people with ID from institutional settings into the community ${ }^{51}$ and as the quality of care of people with ID and of those without ID in residential facilities appears to vary markedly despite the existence of quality standards. ${ }^{52}$ It will be important to follow the trends in polypharmacy over time to see if greater community placement is associated with decreased levels of polypharmacy.

Patterns of multimorbidity comprising mental health and gastrointestinal conditions, epilepsy, endocrine disease, pain and hypertension did appear to drive the high level of drug use noted. Mental health and epilepsy were the strongest and most consistent predictors, while gastrointestinal conditions were associated with excessive polypharmacy only and endocrine disease and hypertension although less prevalent, but were also associated with both levels of polypharmacy. Ouellette-Kuntz reported that comorbid psychiatric diagnoses resulted in multiple medicines at a greater frequency; however, this was at univariate level only, and adjustments for confounding variables were not made. ${ }^{37}$ Haider et $a l^{36}$ collected information on a limited range of conditions that excluded mental health other than depression and pain and thyroid disease, their analysis showed that stroke, cancer, epilepsy, osteoporosis and diabetes, but not depression were significantly associated with polypharmacy in adults.

Eye disease was the most commonly reported condition in the cohort, with half of participants reporting eye disease. Of those reporting eye disease, $27.2 \%$ (98) reported having cataracts, $5 \%$ (18) reported age-related macular degeneration and $2.8 \%$ (10) reported glaucoma. There were a wide range of other eye conditions reported including blepharitis, hypermetropia and bilateral keratoconus. However, reported prevalence of eye preparations was low; $2.8 \%$ reported lubricant preparations, $1.1 \%$ antiglaucoma and miotic preparations. This was reflected in lower excessive polypharmacy and polypharmacy exposure in those with eye conditions; $29.2 \%$ were exposed to excessive polypharmacy, $29.2 \%$ polypharmacy and $69.7 \%$ of those with eye conditions had no polypharmacy. 
Other studies in groups with IDs have also found that antipsychotics and antiepileptics were the most frequently used therapeutic classes. ${ }^{37} 4147$ Antipsychotics were the most frequently reported class, confirming results of previous studies in populations with ID. ${ }^{16495354}$ The levels of reported use of antipsychotics were higher for those who reported excessive polypharmacy, with two thirds reporting use. The widespread use of these agents for mental health conditions and behavioural problems (5) requires further evaluation since there are several risk factors associated with long-term use including weight gain, glucose dysregulation and hyperlipidaemia in the case of the second-generation agents, ${ }^{55}$ and extrapyramidal symptoms and cognitive decline in the case of the first-generation agents. ${ }^{18}$ People with ID may be more susceptible to these side effects compared to the general population ${ }^{57}$ and the prevalence of use is also much lower with estimates of $1.2 \%$ (6) and $2 \%$ (7) in older people in Ireland.

Antiepileptics were the second most commonly reported class $(40 \%)$ in our sample and 7 in 10 of those also reported a doctor's diagnosis of epilepsy. It is likely that in some cases these agents were used for their mood stabilising indications. Anticonvulsants were identified as the second most common class of repeat prescriptions issued to people with ID receiving general practitioner services in the Netherlands. ${ }^{41}$ The rate of use in our study was higher than reported in previous studies, where prevalences of $8 \%$ and $26 \%$ has been reported ${ }^{37}$ but less than reported by van Der Heide $e t a l^{58}$ among an institutionalised population with profound and multiple disability in the Netherlands.

Laxative use was reported by over one-third of the sample, and by three-quarters of those who reported 10 or more medicines, reflecting the high prevalence of constipation established in our study; $43 \%$ reported constipation as a problem and almost one-fifth reporting a doctor's diagnosis of chronic constipation. Our findings also revealed a significant association between laxative use and residential institutions, with over half reporting use, in contrast to over one-quarter in community group homes and $<10 \%$ living independently. These findings are consistent with other studies in the ID population, where high levels of constipation and laxative use have been reported for people with ID living in institutional settings. ${ }^{58-60}$

The findings for people with IDs also contrast with reports on older people including the coincident Irish elderly cohort study, which have found different associations of common diseases ${ }^{61} 62$ and with polypharmacy, with cardiac therapies, analgesics, gastric acid suppressants and antithrombotics as the therapeutic classes most strongly associated with polypharmacy. ${ }^{29} 394663$

\section{Unanswered questions and future research}

Difficulties were encountered making direct comparisons with regard to medicine use in this population compared with other populations with IDs, as definitions of polypharmacy often did not capture total load of medicines in other studies identified. More studies of patterns and prevalence of multiple medicines use in the IDs population are needed, encompassing the broader definitions of polypharmacy and excessive polypharmacy employed in the general population, particularly as life span continues to improve for people with IDs and they acquire age-related morbidities.

Findings in this study identified that multiple medicine use was much greater for people with IDs compared to the Irish population over 50. Furthermore, a different pattern of multiple medicine use for older people with IDs was identified, with greater use of agents to treat mental health and neurological conditions compared to the general population. Therefore, use of appropriateness tools that are used in the elderly have limited applicability to this population. There is a need for specific prescribing guidelines for ageing with IDs, including medication recommendations for particular disease clusters that commonly co-occur in this population. These guidelines would be particularly important to be directed at non-specialist clinicians and pharmacists to aid screening so that appropriate referrals for more specialist treatments can then be made if appropriate. With deinstitutionalisation, people with ID and complex comorbidities are now living in community settings and accessing non-specialist primary care services at greater frequency.

The longitudinal data from Wave Two will transform the study from a cross-sectional analysis into a cohort study and will provide a comprehensive insight into resultant changes in medication patterns as people age, and move into community settings and will enable us to examine the effect of medication use on clinical outcomes.

\section{CONCLUSIONS}

Our findings suggest that a significant proportion of ageing people with IDs are exposed to polypharmacy and excessive polypharmacy to treat multiple morbidities. Furthermore, the distinct patterns of multimorbidity in this population create particular challenges for care providers; those with mental health conditions and epilepsy were more likely to be receiving excessive polypharmacy and in addition, intraclass polypharmacy was associated with antipsychotics, antiepileptics and laxatives, and the place of residence. In contrast, pain, although prevalent was not associated with intensive pharmacotherapy.

This study has begun a process to identify at-risk groups, raise awareness of the unique challenges in providing appropriate pharmacotherapy to this population, and in consequence highlights the need for frequent and rigorous monitoring. This could be achieved through collaborative medication reviews with the incorporation of a clinical pharmacist to help improve 
the quality of prescribing and patient care. ${ }^{64}$ This is particularly important, as ageing people with IDs represent a growing cohort who are particularly vulnerable to adverse drug events, and further work needs to evaluate how this can be provided in the different settings in which older people with IDs live.

\section{Compliance with ethical standards}

The IDS-TILDA study is funded by the Health Research Board and the Department of Health and Children. The lead author (MO) received funding for a $\mathrm{PhD}$ from the Trinity College Dublin Studentship. The funding body did not play a role in the study design, writing of the manuscript. The corresponding author (MO) had full access to the study data, and had final responsibility to submit for publication.

\section{Author affiliations}

${ }^{1}$ School of Pharmacy and Pharmaceutical Sciences, Trinity College Dublin, Dublin, Ireland

${ }^{2}$ IDS-TILDA School of Nursing and Midwifery, Trinity College Dublin, Dublin, Ireland

${ }^{3}$ School of Pharmacy, University of Ljubljana, Ljubljana, Slovenia

${ }^{4}$ Center for Excellence in Aging and Community Wellness, University At Albany, New York, USA

${ }^{5}$ Dean of the Faculty of Health Sciences, Trinity College Dublin, Dublin, Ireland

Acknowledgements The authors would like to thank the people with ID who participated in this study, their families, the services involved, the IDS-TILDA Scientific Advisory Committee, and the Intellectual Disability Consultative Groups for their support. They would like to acknowledge the contributions of Dr Kathleen Bennett and Dr Rachael Carroll. The authors would also like to acknowledge funding for the IDS-TILDA study from the Health Research Board (HRB) and the Department of Health.

Contributors $\mathrm{MO}, \mathrm{MCH}, \mathrm{JP}, \mathrm{PM}$ and MM contributed to the overall conception and design of the study. MO and JP undertook the data extraction. MO carried out the statistical analyses of the study; wrote the first draft of this manuscript. $\mathrm{MO}$ and $\mathrm{MCH}$ revised the manuscript.All authors, external and internal, had full access to all of the data (including statistical reports and tables) in the study and can take responsibility for the integrity of the data and the accuracy of the data analysis. All authors contributed to the interpretation of results and drafting of this manuscript. All authors read and approved the final manuscript.The views expressed are those of the authors and are not necessarily those of the Department of Health, the Health Research Board or Trinity College Dublin. MO and MM are the guarantors.

Funding The IDS-TILDA study is funded by the Health Research Board and the Department of Health. The lead author (MO) received funding for a PhD from the Trinity College Dublin Studentship. The funding body did not play a role in the study design, writing of the manuscript.

\section{Competing interests None declared.}

Ethics approval Ethical approval for the IDS-TILDA study was granted by the Faculty of Health Sciences Ethics Committee, and 138 Intellectual Disability Service Providers.

Provenance and peer review Not commissioned; externally peer reviewed.

Data sharing statement No additional data are available.

Open Access This is an Open Access article distributed in accordance with the Creative Commons Attribution Non Commercial (CC BY-NC 4.0) license, which permits others to distribute, remix, adapt, build upon this work noncommercially, and license their derivative works on different terms, provided the original work is properly cited and the use is non-commercial. See: http:// creativecommons.org/licenses/by-nc/4.0/

\section{REFERENCES}

1. Rojahn J, Schroeder SR, Hoch TA. Self-injurious behavior in intellectual disabilities. Access Online via Elsevier, 2007.

2. van Schrojenstein Lantman-De HM, Metsemakers JF, Haveman MJ, et al. Health problems in people with intellectual disability in general practice: a comparative study. Fam Pract 2000;17:405-7.

3. Haveman M, Heller T, Lee LA, et al. Report on the State of Science on Health Risks and Ageing in People with Intellectual Disabilities. IASSID Special Interest Research Group on Ageing and Intellectual Disabilities/Faculty Rehabilitation Sciences, University of Dortmund, 2009.

4. van Schrojenstein Lantman-de Valk HM, Walsh PN. Managing health problems in people with intellectual disabilities. BMJ 2008;337:a2507.

5. Emerson E, Baines S, Allerton L, et al. Health inequalities and people with learning disabilities in the UK: 2010. Durham: Improving Health \& Lives: Learning Disabilities Observatory, 2010.

6. Haveman M, Heller T, Lee L, et al. Major health risks in aging persons with intellectual disabilities: an overview of recent studies. J Policy Pract Intellect Disabil 2010;7:59-69.

7. Janicki MP, Dalton AJ. Prevalence of dementia and impact on intellectual disability services. Ment Retard 2000;38:276-88.

8. McCallion P, McCarron M, Fahey-McCarthy E, et al. Meeting the end of life needs of older adults with intellectual disabilities. Contemporary and Innovafive Pracfice in Palliafive Care, 2012:255-70

9. McCarron M, Gill M, McCallion P, et al. Health co-morbidities in ageing persons with Down syndrome and Alzheimer's dementia. J Intellect Disabil Res 2005;49:560-6.

10. McCarron M, Swinburne J, Burke E, et al. Patterns of multimorbidity in an older population of persons with an intellectual disability: results from the intellectual disability supplement to the Irish longitudinal study on aging (IDS-TILDA). Res Dev Disabil 2013;34:521-7.

11. Hermans $\mathrm{H}$, Evenhuis HM. Multimorbidity in older adults with intellectual disabilities. Res Dev Disabil 2014;35:776-83.

12. Fletcher R, Loschen E, Stavrakaki C. Diagnostic Manual-Intellectual Disability (DM-ID): a textbook of diagnosis of mental disorders in persons with intellectual disability. NADD, 2007.

13. Cooper SA, Smiley E, Morrison J, et al. Mental ill-health in adults with intellectual disabilities: prevalence and associated factors. Br J Psychiatry 2007;190:27-35.

14. Deb S, Thomas M, Bright C. Mental disorder in adults with intellectual disability. 1: Prevalence of functional psychiatric illness among a community-based population aged between 16 and 64 years. J Intellect Disabil Res 2001;45:495-505.

15. Deb S, Kwok H, Bertelli M, et al. International guide to prescribing psychotropic medication for the management of problem behaviours in adults with intellectual disabilities. World Psychiatry 2009;8: $181-6$.

16. Robertson J, Emerson E, Gregory N, et al. Receipt of psychotropic medication by people with intellectual disability in residential settings. J Intellect Disabil Res 2000;44:666-76.

17. Sullivan WF, Berg JM, Bradley E, et al., Colloquium on Guidelines for the Primary Health Care of Adults with Developmental Disabilities. Primary care of adults with developmental disabilities Canadian consensus guidelines. Can Fam Physician 2011:57:541-53.

18. Jenkins R. Use of psychotropic medication in people with a learming disability. Br J Nurs 2000;9:844-50.

19. Einfeld SL. Guidelines for the use of psychotropic medication in individuals with developmental disabilities. J Intellect Dev Disabil 1990;16:71-3.

20. Etherington J, Sheppard L, Ballinger B, et al. Psychotropic drugs in a hospital for intellectual disability: the story of 18 years. Mental Handicap Res 1995;8:184-93.

21. Stortz JN, Lake JK, Cobigo V, et al. Lessons learned from our elders: how to study polypharmacy in populations with intellectual and developmental disabilities. Intellect Dev Disabil 2014;52:60-77.

22. McCarron M, Swinburne J, Burke E, et al. Growing Older with an Intellectual Disability in Ireland 2011: First Results from the Intellectual Disability Supplement of The Irish Longitudinal Study on Ageing School of Nursing, Trinity College Dublin. 2011.

23. Vandenbroucke JP, von Elm E, Altman DG, et al. Strengthening the reporting of observational studies in epidemiology (STROBE): explanation and elaboration. Int J Surg 2014;12:1500-24.

24. Anatomical Therapeutic Chemical Classification System. http//www. whocc.no/atc-ddd-index/ (accessed 26 Mar 2013).

25. Qato DM, Schumm LP, Johnson M, et al. Medication data collection and coding in a home-based survey of older adults. J Gerontol B Psychol Sci Soc Sci 2009;64(Suppl 1):i86-93. 
26. Directive 2002/46/EC/ of the European Parliament and of to Council of 10 June 2002 of the approximation of the laws of the member states relating to food. Official Journal 2002;183:0051-7 http://eurlex.europa.eu/lexUriServ/LexUriSer.do (accessed 25 Mar 2013).

27. Hovstadius B, Hovstadius K, Åstrand B, et al. Increasing polypharmacy-an individual-based study of the Swedish population 2005-2008. BMC Clin Pharmacol 2010;10:16.

28. Fulton MM, Allen ER. Polypharmacy in the elderly: a literature review. J Am Acad Nurse Pract 2005;17:123-32.

29. Richardson K, Moore PV, Peklar J, et al. Polypharmacy in adults over 50 in Ireland: Opportunities for Cost Saving and Improved Healthcare. The Irish Longitudinal Study on Ageing, Lincoln Place, Trinity College Dublin, Dublin 2, 2012.

30. Barnett K, Mercer SW, Norbury M, et al. Epidemiology of multimorbidity and implications for health care, research, and medical education: a cross-sectional study. Lancet 2012;380:37-43.

31. Kutner MH, Nachtsheim C, Neter J. Applied linear regression models. McGraw-Hill//rwin, 2004.

32. Peduzzi P, Concato J, Kemper E, et al. A simulation study of the number of events per variable in logistic regression analysis. $J$ Clin Epidemiol 1996;49:1373-9.

33. Avery $\mathrm{T}$, Barber N, Ghaleb M, et al. Investigating the prevalence and causes of prescribing errors in general practice. London: The General Medical Council: PRACtICe Study, 2012.

34. Duerden M, Avery T, Payne R. Polypharmacy and medicines optimisation. Kings Fund 2013. http://www.kingsfund.org.uk/sites/ files/kf/field/field_publication_file/polypharmacy-and-medicinesoptimisation-kingsfund-nov13.pdf

35. Greenland S. The effect of misclassification in the presence of covariates. Am J Epidemiol 1980;112:564-9.

36. Haider SI, Ansari Z, Vaughan L, et al. Prevalence and factors associated with polypharmacy in Victorian adults with intellectual disability. Res Dev Disabil 2014;35:3071-80.

37. Cobigo V, Ouellette-Kuntz $\mathrm{H}$, Lake JK, et al. Medication use. In: Lunsky Y, Klein-Geltink JE, Yates EA, eds. Atlas on the primary care of adults with developmental disabilities in Ontario. Toronto, Canada: Institute for Clinical Evaluative Sciences and Centre for Addiction and Mental Health, 2013:117-36; ISBN: 978-1-926850-46-7 (Online). ISBN: 978-1-926850-45-0 (Print). http:// www.ices.on.ca/ /media/Files/Atlases-Reports/2013/ Atlas-on-developmental-disabilities/Full-Report.ashx

38. Bjerrum L, Søgaard J, Hallas J, et al. Polypharmacy: correlations with sex, age and drug regimen A prescription database study. Eur $J$ Clin Pharmacol 1998;54:197-202.

39. Haider SI, Johnell K, Thorslund M, et al. Analysis of the association between polypharmacy and socioeconomic position among elderly aged $\geq 77$ years in Sweden. Clin Ther 2008;30:419-27.

40. Slabaugh SL, Maio V, Templin M, et al. Prevalence and risk of polypharmacy among the elderly in an outpatient setting: a retrospective cohort study in the Emilia-Romagna region, Italy. Drugs Aging 2010;27:1019-28.

41. Straetmans JM, van Schrojenstein Lantman-de HM, Schellevis FG, et al. Health problems of people with intellectual disabilities: the impact for general practice. Br J Gen Pract 2007;57:64-6.

42. Stolker JJ, Heerdink ER, Leufkens HG, et al. Determinants of multiple psychotropic drug use in patients with mild intellectual disabilities or borderline intellectual functioning and psychiatric or behavioral disorders. Gen Hosp Psychiatry 2001;23:345-9.

43. Qato DM, Alexander GC, Conti RM, et al. Use of prescription and over-the-counter medications and dietary supplements among older adults in the United States. JAMA 2008;300:2867-78.

44. Hajjar ER, Cafiero AC, Hanlon JT. Polypharmacy in elderly patients. Am J Geriatr Pharmacother 2007;5:345-51.
45. Stewart RB, Cooper JW. Polypharmacy in the aged. Drugs Aging 1994:4:449-61.

46. Jyrkkä J, Enlund $\mathrm{H}$, Korhonen MJ, et al. Patterns of drug use and factors associated with polypharmacy and excessive polypharmacy in elderly persons. Drugs Aging 2009;26:493-503.

47. Doan TN, Lennox NG, Taylor-Gomez M, et al. Medication use among Australian adults with intellectual disability in primary healthcare settings: a cross-sectional study. J Intellect Dev Disabil 2013;38:177-81.

48. Kiernan C, Reeves D, Alborz A. The use of anti-psychotic drugs with adults with learning disabilities and challenging behaviour. $J$ Intellect Disabil Res 1995;39:263-74.

49. Hurley AD, Folstein M, Lam N. Patients with and without intellectual disability seeking outpatient psychiatric services: diagnoses and prescribing pattern. J Intellect Disabil Res 2003;47:39-50.

50. Vetrano DL, Tosato M, Colloca G, et al., SHELTER Study. Polypharmacy in nursing home residents with severe cognitive impairment: Results from the SHELTER Study. Alzheimers Dement 2013;9:587-93.

51. Report of the Working Group on Congregated Settings Homes. Time to Move on from Congregated Settings: A strategy for Community Inclusion. Health Service Executive, 2011.

52. Inclusion Ireland. A working paper on the first 50 Health Information andQuality Authority (Hiqa) inspections of residential services or people with disabilities, 2015.

53. Ahmed Z, FRASER W, Kerr MP, et al. Reducing antipsychotic medication in people with a learning disability. Br J Psychiatry 2000:176:42-6.

54. de Kuijper G, Hoekstra P, Visser F, et al. Use of antipsychotic drugs in individuals with intellectual disability (ID) in the Netherlands: prevalence and reasons for prescription. $J$ Intellect Disabil Res 2010;54:659-67.

55. Gareri P, De Fazio P, De Fazio S, et al. Adverse effects of atypical antipsychotics in the elderly: a review. Drugs Aging 2006;23: 937-56.

56. Matson JL, Mahan S. Antipsychotic drug side effects for persons with intellectual disability. Res Dev Disabil 2010;31:1570-6.

57. Arnold LE. Clinical pharmacological issues in treating psychiatric disorders of patients with mental retardation. Ann Clin Psychiatry 1993;5:189-97.

58. van der Heide DC, van der Putten A, van den Berg P, et al. The documentation of health problems in relation to prescribed medication in people with profound intellectual and multiple disabilities. J Intellect Disabil Res 2009;53:161-8.

59. Böhmer C, Taminiau J, Klinkenberg-Knol E, et al. The prevalence of constipation in institutionalized people with intellectual disability. J Intellect Disabil Res 2001;45:212-18.

60. Evenhuis $\mathrm{H}$. Medical aspects of ageing in a population with intellectual disability: III. Mobility, internal conditions and cancer. J Intellect Disabil Res 1997:41:8-18.

61. Haveman M, Perry J, Salvador-Carulla L, et al. Ageing and health status in adults with intellectual disabilities: results of the European POMONA II study. J Intellect Dev Disabil 2011;36: 49-60.

62. McCallion $\mathrm{P}$, Burke $\mathrm{E}$, Swinburne J, et al. The influence of environment, predisposing, enabling and need variables on personal health choices of adults with intellectual disability. 2013.

63. Barat I, Andreasen F, Damsgaard EMS. The consumption of drugs by 75 -year-old individuals living in their own homes. Eur $\mathrm{J}$ Clin Pharmacol 2000;56:501-9.

64. Kaboli PJ, Hoth AB, McClimon BJ, et al. Clinical pharmacists and inpatient medical care: a systematic review. Arch Intern Med 2006;166:955 